\title{
Perancangan Sistem Informasi Pembelajaran Algoritma dan Pemrograman Berbasis Web pada Program Studi Teknik Informatika STMIK ERESHA
}

\author{
Samsudin $^{1}$, Indrawan $^{2}$, Sri Mulyati ${ }^{3}$ \\ ${ }^{1,2}$ Teknik Informatika, STMIK ERESHA, Jl. Raya Puspitek no. 11 Buaran, Serpong, Kota Tangerang \\ Selatan, Banten 15310 \\ ${ }^{3}$ Teknik Informatika, Universitas Pamulang, Jl. Raya Puspitek no. 46 Buaran, Serpong, Kota Tangerang \\ Selatan, Banten 15310 \\ e-mail: ${ }^{1}$ sam.unpam@gmail.com, ${ }^{3}$ dosen00391@unpam.ac.id
}

Submitted Date: December $16^{\text {th }}, 2020$

Revised Date: January $02^{\text {nd }}, 2021$
Reviewed Date: December $30^{\text {th }}, 2020$

Accepted Date: January $05^{\text {th }}, 2021$

\begin{abstract}
This study aims to present web-based algorithm and programming materials in order to increase interest and motivation in studying in the informatics engineering study program, this learning system is made so that all who want to learn algorithms and programming easily get solutions from the material and videos that are available on the web page. And the existence of this web-based learning information system can provide material archive storage and exercises so that there is no more loss of material or exercise files. This application is created using the PHP and MYSQL programming languages.
\end{abstract}

Keywords: Information System; Learning; PHP; MySQL

\begin{abstract}
Abstrak
Penelitian ini bertujuan menyajikan materi algoritma dan pemrograman berbasis web guna meningkatkan minat serta motivasi dalam belajar di prodi teknik informatika, sistem pembelajaran ini dibuat agar semua yang ingin belajar algoritma dan pemrograman dengan mudah mendapatkan solusi dari materi serta video yang telah tersedia di halaman web. Serta dengan adanya sistem informasi pembelajaran berbasis web ini dapat menyediakan penyimpanan arsip materi dan latihan agar tidak ada lagi kehilangan berkas materi atau latihan. Aplikasi ini dibuat dengan menggunakan bahasa pemrograman PHP dan MySQL
\end{abstract}

Kata Kunci: Sistem Informasi; Pembelajaran; $P H P ; M y S Q L$

\section{Pendahuluan}

Perkembangan saat ini di era teknologi informasi dapat meningkatkan kinerja dan memungkinkan berbagai kegiatan yang dapat dilaksanakan dengan cepat, tepat dan akurat sehingga akan meningkatkan produktivitas. Selain itu, perkembangan teknologi informasi juga telah banyak mempengaruhi berbagai bidang kehidupan, karena teknologi informasi ditujukan untuk membantu pekerjaan dengan menyediakan informasi dan melakukan berbagai tugas yang berhubungan dengan pengolahan informasi (Hanum \& Saifudin, 2019). Kebutuhan akan teknologi dan informasi sangat tinggi untuk membantu berbagai jenis bidang pekerjaan manusia (Taufiq, Magfiroh, Yusup, \& Yulianti,
2020). Teknologi informasi telah berfungsi sebagai pemasok ilmu pengetahuan.

Ilmu pengetahuan dan teknologi selalu berkembang dan mengalami kemajuan, sesuai dengan perkembangan zaman dan perkembangan cara berpikir manusia. Dari berbagai hasil kemajuan teknologi informasi terdapat perkembangan web. Web mempunyai peranan yang sangat penting dalam perkembangan dunia pendidikan. Salah satu manfaat web dalam dunia pendidikan adalah sebagai media informasi. Dunia pendidikan juga tidak lepas dari pengaruh teknologi informasi. Keterbatasan ruang dan waktu menjadi kendala utama dalam peningkatan mutu dan kualitas pendidikan.

Perkembangan teknologi informasi saat ini sangat mempengaruhi sistem informasi yang 
merupakan aspek sangat penting bagi siswa untuk mendukung kelangsungan perkembangan dalam belajar. Pembelajaran merupakan suatu sistem atau proses membelajarkan pembelajar yang direncanakan, dilaksanakan dan dievaluasi secara sistematis agar pembelajar dapat mencapai tujuantujuan pembelajaran secara efektif dan efesien. (Komalasari, 2003)

Dalam permasalahan ini, menyampaikan informasi yang biasanya hanya melalui mediamedia cetak dirasakan kurang efektif, karena saat ini sudah banyak orang yang menggunakan internet sebagai media informasi. Penggunaan teknologi informasi, dalam hal ini internet dipercaya mampu meningkatkan mutu dan kualitas pendidikan. Salah satu upaya untuk meningkatkan mutu pendidikan yaitu dengan memanfaatkan teknologi informasi yaitu dengan menggunakan teknologi web dalam mendukung proses kegiatan belajar mengajar.

\section{Metodologi}

\subsection{Definisi Pembelajaran}

Pembelajaran adalah proses interaksi peserta didik dengan pendidik dan sumber belajar pada suatu lingkungan belajar. Pembelajaran merupakan bantuan yang diberikan pendidik agar dapat terjadi proses perolehan ilmu dan pengetahuan, penguasaan kemahiran dan tabiat, serta pembentukan sikap dan kepercayaan pada peserta didik (Komara, 2014). Dengan kata lain, pembelajaran adalah proses untuk membantu peserta didik agar dapat berjalan dengan baik.

\subsection{Algoritma dan Pemrograman}

Para ahli sejarah matematika menemukan asal kata Algorism yang berasal dari nama penulis buku arab yang terkenal yaitu Abu Ja"far Muhammad Ibnu Musa Al Khuwarizmi. AlKhuwarizmi dibaca orang barat menjadi Algorism. Al-Khuwarizmi menulis buku yang berjudul Kitab Al Jabar Wal-Muqabala yang artinya "Buku pemugaran dan pengurangan" (The book of restoration and reduction). Dari judul buku itu kita juga memperoleh akar kata "Aljabar" (Algebra). Perubahan kata dari Algorism menjadi Algorithm muncul karena kata Algorism sering dikelirukan dengan Arithmetic, sehingga akhiran sm berubah menjadi -thm. Karena perhitungan dengan angka Arab sudah menjadi hal yang biasa. Maka lambat laun kata Algorithm berangsurangsur dipakai sebagai metode perhitungan (komputasi) secara umum, sehingga kehilangan makna kata.
Menurut Goodman Hedet Niemi, algoritma adalah urutan terbatas dari operasi-operasi terdefinisi dengan baik, yang masing-masing membutuhkan memori dan waktu yang terbatas untuk menyelesaikan suatu masalah.

Menurut Sunarto, Program adalah sekumpulan instruksi yang diwujudkan dalam bentuk bahasa, kode skema, ataupun bentuk lain, yang apabila digabungkan dengan media yang dapat dibaca dengan komputer akan mampu membuat komputer bekerja untuk melakukan fungsi-fungsi khusus, termasuk persiapan dalam merancang instruksi-instruksi tersebut.

Dari pengertian algoritma dan program (pemrograman) diatas, kesimpulan dari pengertian keduanya, algoritma (singkatnya) adalah "langkahlangkah sistematis", sedangkan pemrograman adalah "kegiatan membuat program", dalam hal ini program komputer, dengan demikian algoritma pemrograman adalah "Langkah-langkah sistematis dan logis untuk membuat suatu program komputer dengan bantuan bahasa pemrograman untuk menyelesaikan masalah dan mencapai tujuan tertentu".

\subsection{Hypertext Preprocessor (PHP)}

PHP adalah bahasa server-side-scripting yang menyatu dengan $H T M L$ untuk membuat halaman web yang dinamis (Arief, 2011). Karena php merupakan server-side-scripting maka sintaks dan perintah-perintah PHP akan diesksekusi di server kemudian hasilnya akan dikirimkan ke browser dengan format $H T M L$.

\section{$2.4 X A M P P$}

$X A M P P$ merupakan paket $P H P$ dan $M y S Q L$ berbasis open source, yang dapat digunakan sebagai tool pembantu pengembangan aplikasi berbasis PHP (Riyanto, 2010). XAMPP mengkombinasikan beberapa paket perangkat lunak berbeda ke dalam satu paket. XAMPP sendiri memiliki singkatan yang cukup panjang yang berarti :

1. X : Program ini dapat dijalankan dibanyak sistem operasi, seperti Windows, Linux, Mac OS, dan Solaris.

2. A : Apache, merupakan aplikasi web server. Tugas utama Apache adalah menghasilkan halaman web yang benar kepada user berdasarkan kode PHP yang dituliskan oleh pembuat halaman web.

3. $\mathrm{M}: M y S Q L$, merupakan aplikasi database server. Perkembangannya disebut $S Q L$ yang merupakan kepanjangan dari Structured 
Query Language. SQL merupakan bahasa terstruktur yang digunakan untuk mengolah database. $M y S Q L$ dapat digunakan untuk membuat dan mengelola database beserta isinya. Kita dapat memanfaatkan $M y S Q L$ untuk menambahkan, mengubah, dan menghapus data yang berada dalam database.

4. $\mathrm{P}: P H P$, bahasa pemrograman web. Bahasa pemrograman PHP merupakan bahasa pemrograman untuk membuat web yang bersifat server-side scripting. PHP memungkinkan kita untuk membuat halaman web yang bersifat dinamis. Sistem manajemen basis data yang sering digunakan bersama $P H P$ adalah $M y S Q L$.

5. P : Perl, bahasa pemrograman.

\section{Tabel 1 Folder penting XAMPP}

\begin{tabular}{|l|l|l|}
\hline No & Nama & Penjelasan \\
\hline 1. & Apache & $\begin{array}{l}\text { Folder utama dari Apache } \\
\text { Webserver }\end{array}$ \\
\hline 2. & Htdocs & $\begin{array}{l}\text { Folder utama untuk } \\
\text { menyimpan data - data latihan } \\
\text { web, baik PHP maupun HTML } \\
\text { biasa. Pada folder ini, Anda } \\
\text { dapat membuat subfolder } \\
\text { sendiri untuk menge- } \\
\text { lompokkan file latihannya. } \\
\text { Semua folder dan file program } \\
\text { di htdocs bisa diakses dengan } \\
\text { mengetikkan } \\
\text { http://localhost/ di browser. }\end{array}$ \\
\hline 3. & MySQL & $\begin{array}{l}\text { Folder utama untuk database } \\
\text { MySQL server. Di dalam } \\
\text { terdapat subfolder data } \\
\text { (lengkapnya } \\
\text { C:/xampp/mysql/data untuk } \\
\text { merekam semua nama } \\
\text { database, serta subfolder bin } \\
\text { yang berisi tools klien dan } \\
\text { server MySQL. }\end{array}$ \\
\hline $\begin{array}{l}\text { Folder utama untuk program } \\
\text { PHP }\end{array}$ \\
\hline 4. & $P H P$
\end{tabular}

\subsection{Metode Pengembangan Sistem}

Metode pengembangan sistem yang akan digunakan adalah secara terstruktur yaitu menggunakan Waterfall Model yang mengusulkan sebuah pendekatan kepada perkembangan perangkat lunak yang sistematik dan sekuensial dimulai pada tingkat dan kemajuan sistem pada seluruh analisis, desain, kode implementasi, dan pemeliharaan. Pemodelan pengembangan sistem teknik waterfall meliputi aktifitas-aktifitas seperti berikut :

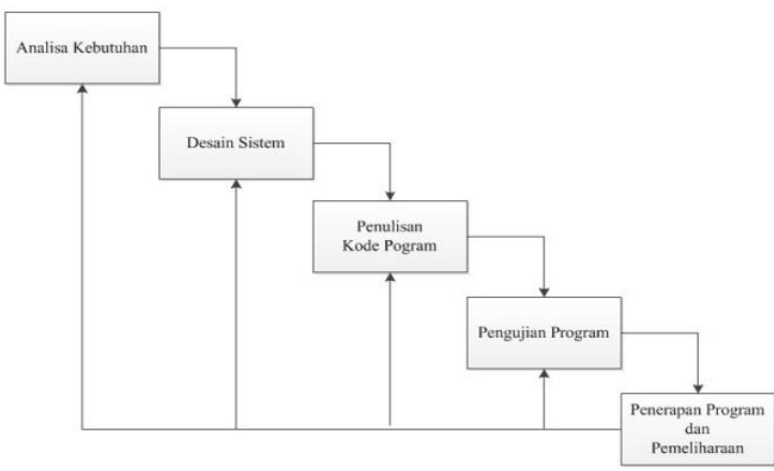

Gambar 1 Skema Model Waterfall

1. Analisis Sistem (Analysis)

Langkah ini merupakan analisa terhadap kebutuhan sistem. Pengumpulan data dalam tahap ini bisa melakukan sebuah penelitian, wawancara atau studi literatur.

2. Desain Sistem (Design)

Tahapan di mana dilakukan penuangan pikiran dan perancangan sistem terhadap solusi dari permasalahan yang ada dengan menggunakan perangkat pemodelan sistem seperti diagaram alir data (Data Flow Diagram), diagram hubungan entitas (Entity Relationship Diagram) serta struktur dan basis data.

3. Penulisan Kode Program (Code)

Merupakan penerjemahan design dalam bahasa yang bisa dikenali oleh komputer. Maka design diubah ke dalam bahasa pemrograman melalui proses coding.

4. Pengujian Program (Testing)

Untuk menjamin kualitas sistem/aplikasi yang dikembangkan harus melalui tahap pengujian (Pratala, Asyer, Prayudi, \& Saifudin, 2020). Pengujian merupakan suatu rangkaian aktivitas yang terencana dan sistematis untuk menguji atau mengevaluasi kebenaran fungsi aplikasi berdasarkan desain kasus uji (test case) yang spesifik (Yulistina, dkk, 2020). Pengujian terhadap perangkat lunak sangat penting dilakukan dengan tujuan untuk memberikan jaminan kualitas perangkat lunak yang dihasilkan agar bebas dari terjadinya kesalahan (Debiyanti, dkk, 2020). 
5. Penerapan Program dan Pemeliharaan (Maintenance)

Perangkat lunak yang sudah disampaikan kepada pelanggan pasti akan mengalami perubahan. Perubahan tersebut bisa karena mengalami kesalahan baru yang tidak ditemukan sebelumnya, atau ada penambahan fitur-fitur yang belum ada pada software tersebut.

\section{Analisa dan Perancangan}

\subsection{Analisa Kebutuhan}

Dalam perancangan web ini penulis membuat sebuah web yang akan memudahkan untuk mendapatkan materi pelajaran algoritma dan pemrograman dan juga melatih penguasaan mereka terhadap materi. Atas dasar analisa kebutuhan, penulis membagi web ini menjadi 2 (dua) bagian.

1. Halaman Pengunjung

Halaman pengunjung adalah halaman yang digunakan untuk memberikan informasi kepada pengunjung yang mengunjungi web ini supaya mengetahui kegunaan dari web ini.

2. Halaman Admin

Halaman admin adalah halaman yang digunakan sebagai halaman administrasi untuk mengelola data seperti data materi pelajaran, mengola data user, dll.

\subsection{Entity Relationship Diagram (ERD)}

Menurut Hanif Al Fatta (2007: 119) mengemukakan entity relationship diagram adalah gambar atau diagram yang menunjukan informasi, dibuat, disimpan dan digunakan dalam sistem bisnis. Adapun gambaran rancangan ERD Perancangan Sistem Informasi Pembelajaran Algoritma dan pemrograman adalah sebagai berikut :

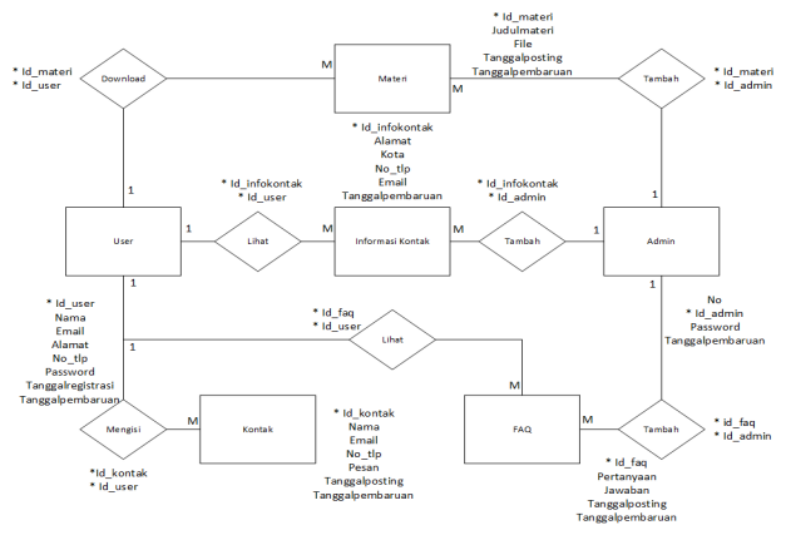

Gambar 3 Entity Relationship Diagram (ERD)

\subsection{Activity Diagram yang Akan Diajukan}

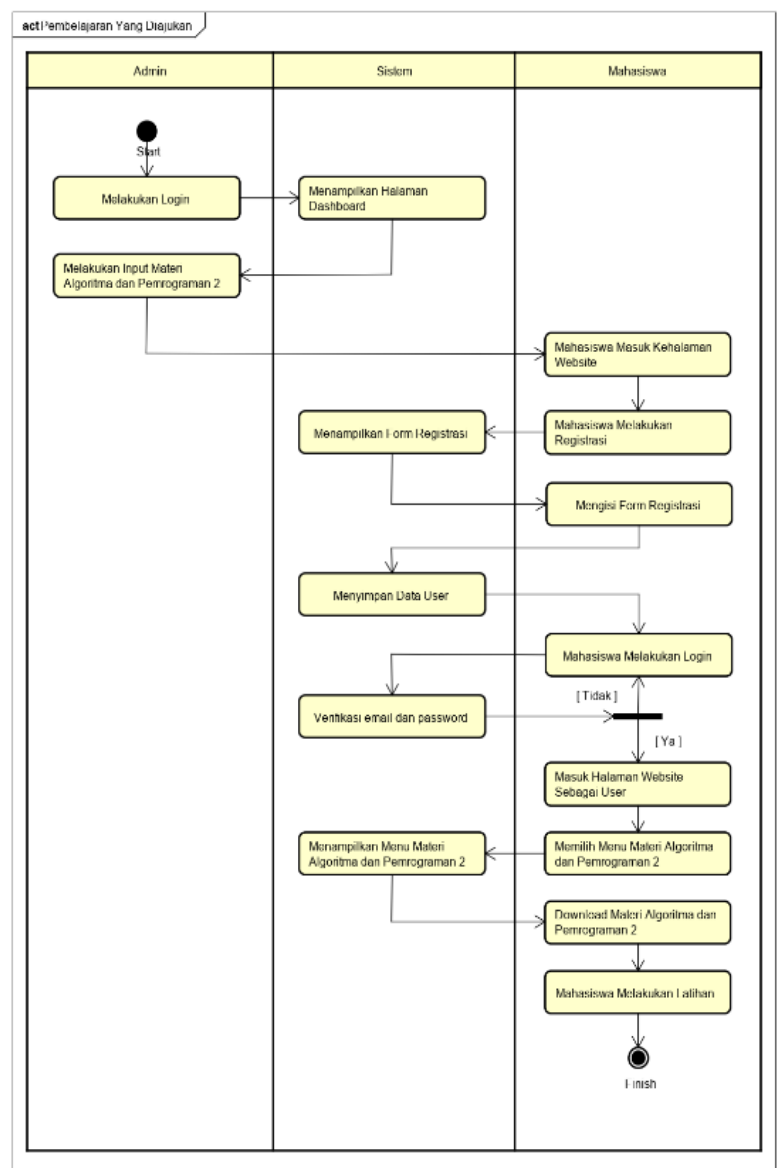

Gambar 2 Activity Diagram Pembelajaran yang Akan Diajukan

\subsection{Use Case Diagram Sistem yang Akan Diajukan}

Use case diagram adalah rangkaian atau uraian sekelompok yang saling terkait dan saling membentuk sistem secara teratur yang dilakukan atau diwakili oleh sebuah actor. Berdasarkan analisa sistem informasi pembelajaran algoritma dan pemrograman yang telah dilakukan sebelumnya, maka perancangan yang diajukan pada sistem dapat dilihat pada gambar di bawah ini. 


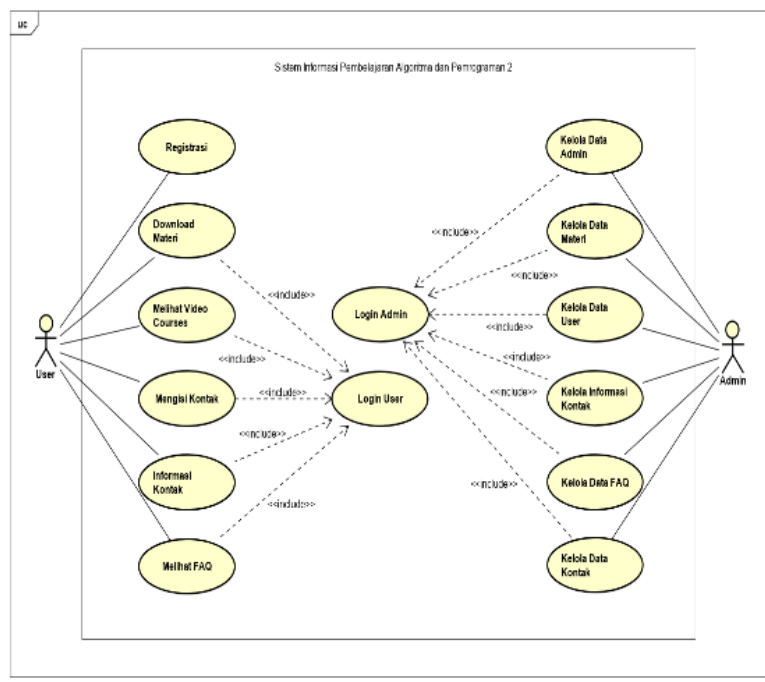

Gambar 4 Diagram Model Use Case

\subsection{Sequence Diagram}

Sequence Diagram adlah suatu diagram yang menggambarkan interaksi antar objek dan mengidentifikasikan komunikasi diantara objekobjek tersebut. Diagram ini juga menunjukan serangkaian pesan yang diperuntukan oleh objekobjek untuk melakukan sesuatu tugas atau aksi tertentu. Berikut ini adalah Sequence Diagram dari Perancangan Sistem Informasi Pembelajaran Algoritma dan pemrograman Berbasis Web Pada STMIK ERESHA.

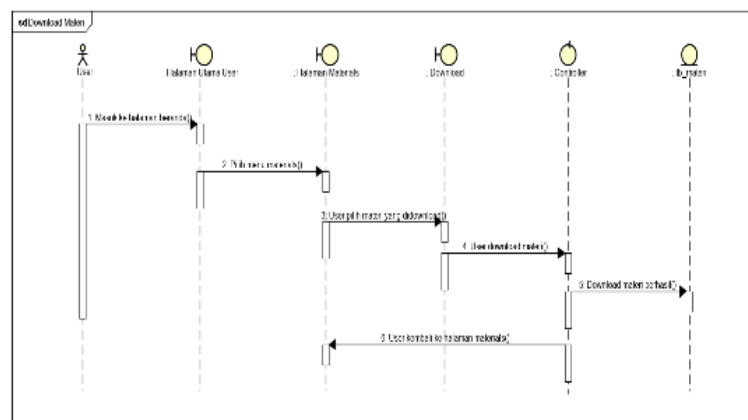

Gambar 5 Sequence Diagram Download Materi

\subsection{Class Diagram}

Dari penelitian sistem informasi pembelajaran algoritma dan pemrograman berbasis web pada STMIK ERESHA yang sudah dirancang, maka class diagram nya seperti di bawah ini:

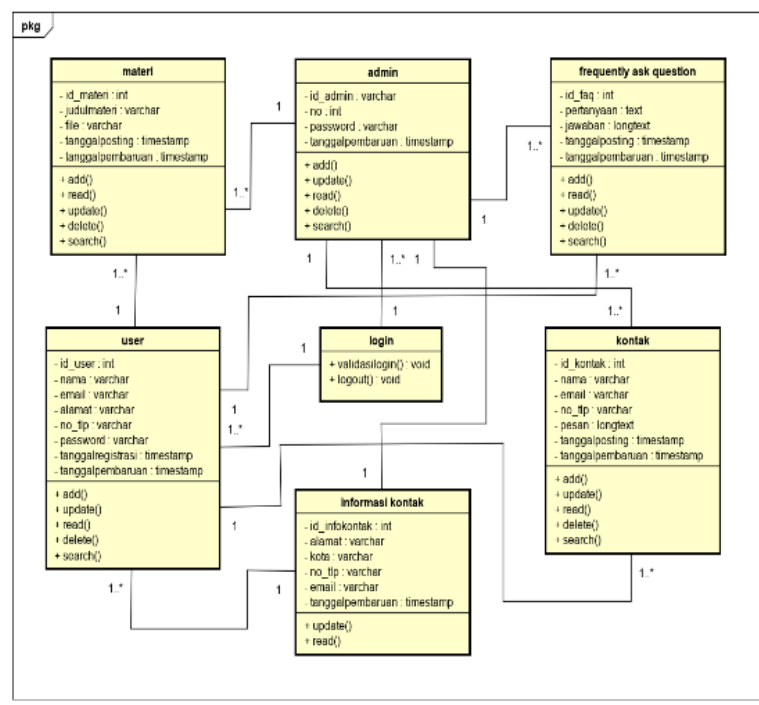

Gambar 6 Class Diagram

\section{Implementasi}

\subsection{Implementasi}

Antarmuka adalah komponen sistem yang bersentuhan langsung dengan pengguna. Implementasi antar muka dilakukan dengan setiap tampilan program yang dibangun. Berikut ini adalah implementasi antarmuka web Sistem Informasi Pembelajaran Algoritma dan pemrograman Berbasis Web pada STMIK ERESHA yang dibuat.

\subsection{Halaman User}

Halaman User adalah bagian visual dari web yang memastikan bagaimana seorang user berinteraksi dengan aplikasi atau web tersebut serta bagaimana informasi ditampilkan di layarnya.

a. Halaman Registrasi

Halaman ini berfungsi untuk menampilkan form pendaftaran untuk user baru yang ingin masuk ke halaman beranda web.

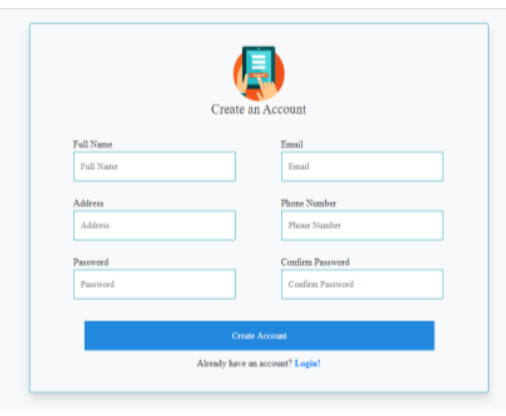

Gambar 7 Tampilan Halaman Registrasi

b. Halaman Login User 
Halaman Login User adalah halaman awal yang ditampilkan pada saat membuka halaman login user, user dapat mengisi form email dan password yang telah di registrasi. Halaman ini berfungsi agar user dapat masuk kedalam halaman beranda web.

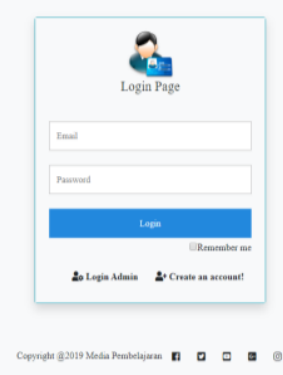

Gambar 8 Tampilan Halaman Login User

\section{c. Halaman Material}

Pada halaman ini user dapat mendownload materi dan mencari materi yang dibutuhkan sesuai judul materi ataupun urutan materi. Halaman ini berisi kumpulan materi yang berfungsi untuk mempermudah dalam proses belajar.

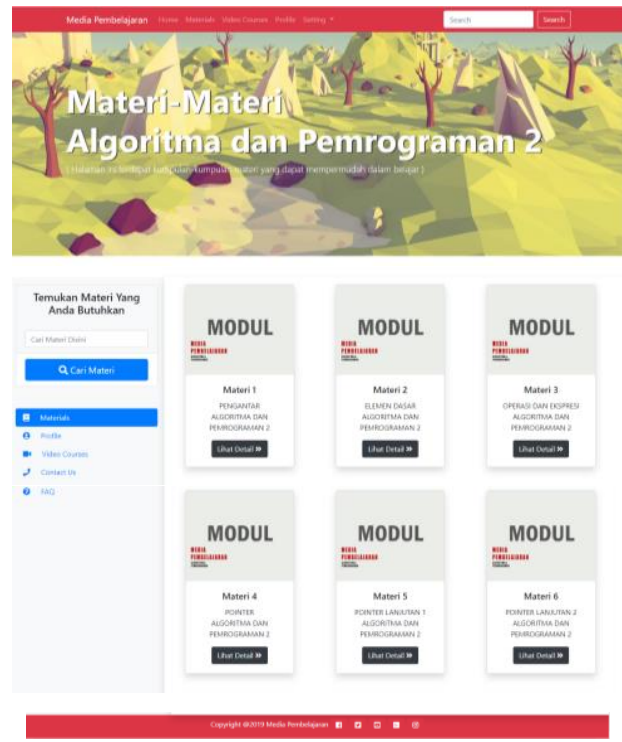

Gambar 9 Tampilan Halaman Material

\subsection{Halaman Admin}

Halaman Admin adalah halaman yang digunakan untuk mengelola data ataupun hal lain yang berhubungan dengan halaman utama web. Gambar 10 sampai dengan gambar 16 merupakan gambaran halaman - halaman yang ada pada halaman admin (backend) untuk manajemen konten yang ada pada web Pembelajaran Algoritma dan pemrograman . Berikut ini adalah bagian tampilan dari halaman admin :

a. Halaman Login Admin

Halaman Login Admin adalah halaman awal yang ditampilkan pada saat membuka halaman login admin (backend), admin dapat mengisi form id dan password dengan benar. Halaman ini berfungsi agar admin dapat masuk kedalam halaman dashboard.

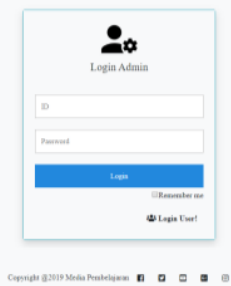

Gambar 10 Tampilan Halaman Login Admin

\section{b. Halaman Dashboard}

Halaman Dashbord merupakan halaman pusat control panel yang berfungsi untuk mengatur semua kegiatan di web dan kelola data seperti kelola admin, kelola materi, kelola data user, kelola informasi kontak, kelola data kontak, kelola FAQ. Di halaman ini terdapat data master dan informasi sosial media web tersebut.

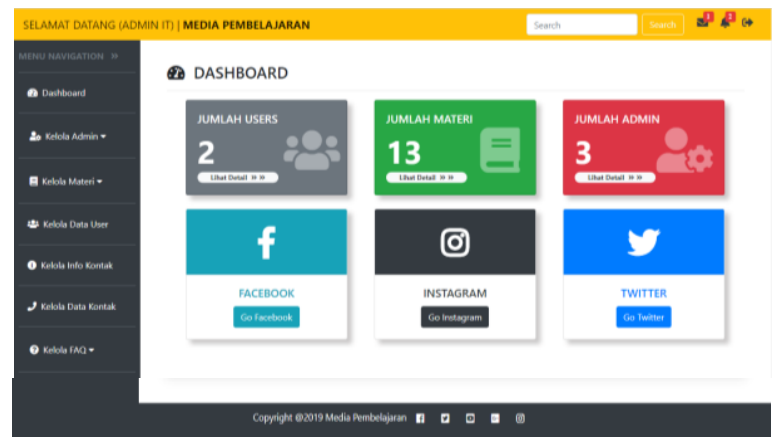

Gambar 11 Tampilan Halaman Dashboard Admin

c. Halaman Data Admin

Halaman Data Admin, pada halaman ini menampilkan list data admin dan terdapat tombol tambah admin, cari data admin. Halaman ini hanya dapat diakses oleh admin. 


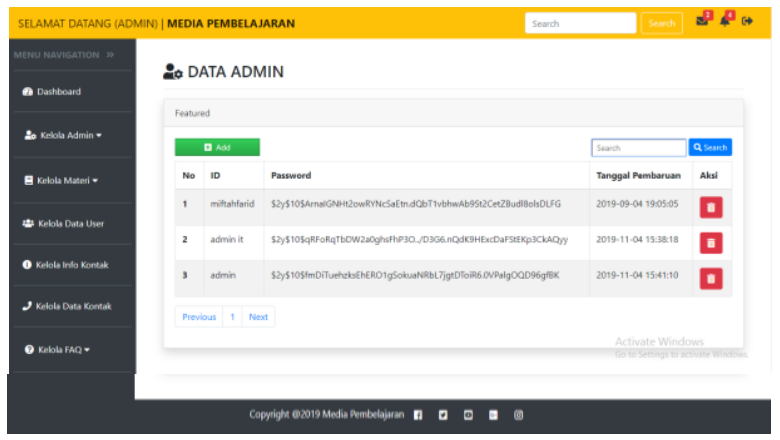

Gambar 12 Tampilan Halaman Data Admin

\section{d. Halaman Update Data Admin}

Halaman Update Data Admin, pada halaman ini menampilkan form yang berfungsi untuk mengubah id dan password admin yang sedang login. Setelah berhasil update maka admin kembali login ulang dengan id dan password baru. Halaman ini hanya dapat diakses oleh admin.

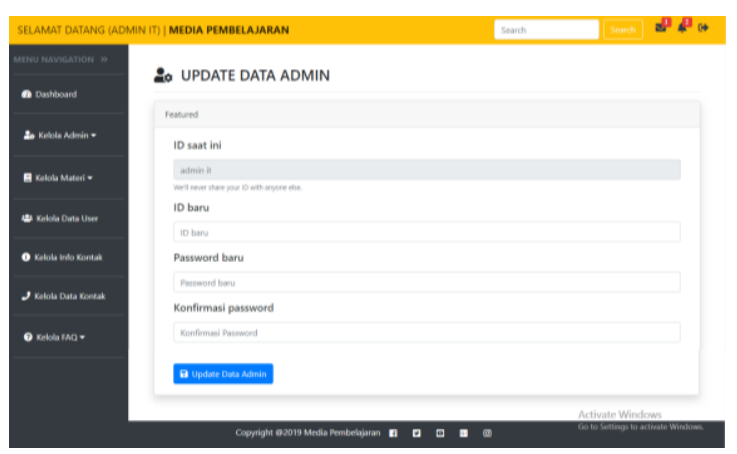

Gambar 13 Tampilan Halaman Update Data Admin

\section{e. Halaman Data Materi}

Halaman Data Materi, pada halaman ini menampilkan list data materi dan terdapat tombol cari data materi, edit data materi, dan hapus data materi. Halaman ini hanya dapat diakses oleh admin

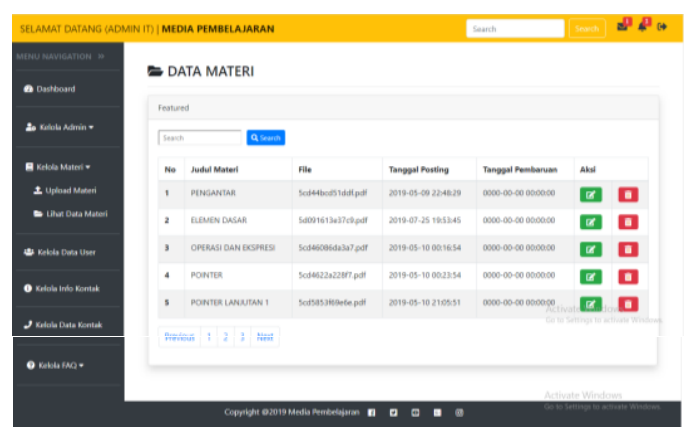

Gambar 14 Tampilan Halaman Data Materi

\section{f. Halaman Upload Materi}

Halaman Upload Materi, pada halaman ini menampilkan form judul materi dan upload file yang akan ditampilkan di halaman material user. Halaman ini hanya dapat diakses oleh admin.

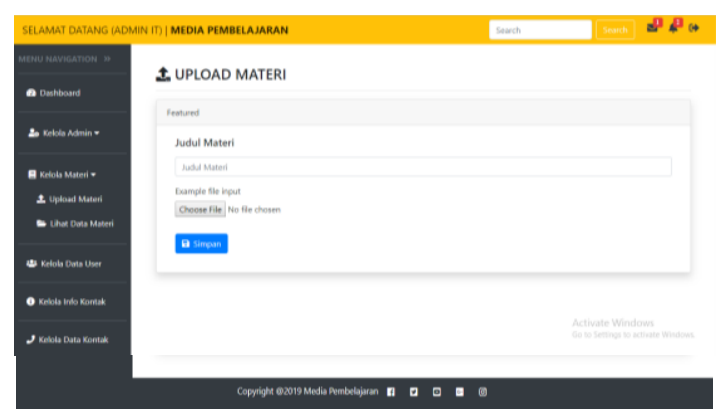

Gambar 15 Tampilan Halaman Upload Materi

\section{g. Halaman Data User}

Halaman Data User, pada halaman ini menampilkan list data user dan terdapat tambah data user, detail data user yang berfungsi untuk menampilkan informasi data user secara lengkap. Terdapat juga edit data user, hapus data user didalam tombol detail. Halaman ini hanya dapat diakses oleh admin.

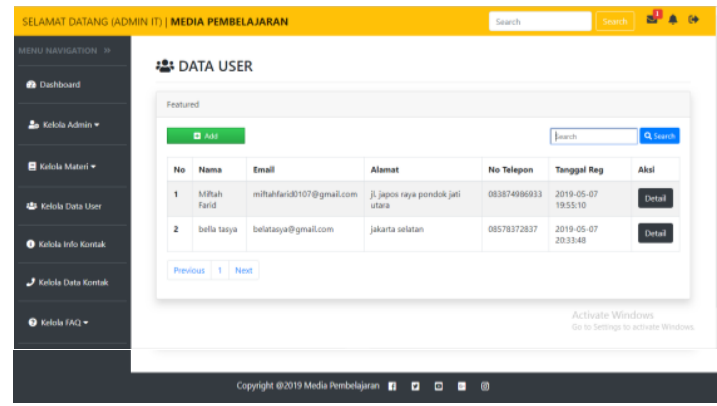

Gambar 16 Tampilan Halaman Data User

\section{Kesimpulan}

Berdasarkan implementasi dan pengujian pada bab-bab sebelumnya, maka penulis mengambil kesimpulan bahwa perancangan sistem informasi pembelajaran algoritma dan pemrograman berbasis web pada STMIK ERESHA, sebagai berikut:

a. Dengan adanya sistem informasi pembelajaran algoritma dan pemrograman berbasis web pada STMIK ERESHA ini dapat memudahkan guru dalam melakukan pengolahan materi serta dapat melakukan pemberian materi pembelajaran dengan mudah. 
b. Dengan adanya sistem informasi pembelajaran algoritma dan pemrograman berbasis web pada STMIK ERESHA ini dapat menyimpan arsip materi dan latihan agar tidak ada lagi kehilangan berkas materi atau latihan.

c. Dengan adanya sistem informasi pembelajaran algoritma dan pemrograman berbasis web pada STMIK ERESHA ini dapat menyelesaikan permasalahan dalam proses belajar-mengajar, sehingga siswa dapat lebih memahami materi yang disampaikan.

\section{Saran}

Dari hasil analisa dan perancangan sistem informasi pembelajaran algoritma dan pemrograman berbasis web pada STMIK ERESHA ini, penulis menyadari bahwa masih banyak kekurangan dan kesalahan pada sistem ini. Adapun saran untuk mengembangkan sistem informasi pembelajaran algoritma dan pemrograman berbasis web pada STMIK ERESHA ini sebagai berikut:

a. Perlu dilakukannya sosialisasi kepada seluruh user atau pengguna agar sistem yang baru diusulkan ini dapat berjalan dengan baik.

b. Agar sistem pembelajaran yang sudah terkomputerisasi harus terus menerus dilakukan backup data agar keamanan dapat terus terjaga dan apabila terdapat kendala sebaiknya diselesaikan dengan pihak yang terkait sehingga hasil yang diinginkan dapat tercapai dengan maksimal.

c. Agar rancangan sistem pembelajaran berbasis web yang telah dibuat penulis diharapkan dapat diimplementasikan guna mendukung proses perkembangannya dan memberikan kemudahan dalam pelaksanaan sistem pembelajaran.

\section{Referensi}

Arief, M. R. (2011). Pemrograman Web Dinamis Menggunakan Php dan Mysql. Yogyakarta: ANDI.

Debiyanti, D., Sutrisna, S., Budrio, B., Kamal, A. K., \& Yulianti, Y. (2020). Pengujian Black Box pada Perangkat Lunak Sistem Penilaian Mahasiswa Menggunakan Teknik Boundary Value Analysis. Jurnal Informatika Universitas Pamulang, 5(2), 162-166. doi:10.32493/informatika.v5i2.5446

Fatta, H. A. (2007). Analisis dan Perancangan Sistem Informasi. Andi. Yogyakarta.
Hanum, W. S., \& Saifudin, A. (2019). Rancang Bangun Aplikasi Panduan Pariwisata di Kabupaten Banyuwangi Mobile Berbasis Android. Jurnal Teknologi Sistem Informasi dan Aplikasi, 2(2), 59-65. doi:10.32493/jtsi.v2i2.2798

Kadir, A. (2003). Pengenala $n$ Sistem Informasi. Yogyakarta: Penerbit ANDI.

Komara, E. 2014. Belajar dan Pembelajaran Interaktif. Bandung: PT Refika Adiatama.

Pratala, C. T., Asyer, E. M., Prayudi, I., \& Saifudin, A. (2020). Pengujian White Box pada Aplikasi Cash Flow Berbasis Android Menggunakan Teknik Basis Path. Jurnal Informatika Universitas Pamulang, 5(2), 111-119. doi:10.32493/informatika.v5i2.4713

Riyanto. 2010. Sistem Informa si Penjualan Dengan PHP Dan MySQL. Gava Media. Yogyakarta.

Taufiq, R., Magfiroh, D. A., Yusup, D., \& Yulianti, Y. (2020). Analisis dan Desain Sistem Informasi Pembayaran Sumbangan Pembinaan Pendidikan (SPP) di Di SMK Avicena Rajeg. Jurnal Teknologi Sistem Informasi dan Aplikasi, 3(1), 15-21. doi:10.32493/jtsi.v3i1.4308

Yulistina, S. R., Nurmala, T., Supriawan, R. M., Juni, S. H., \& Saifudin, A. (2020). Penerapan Teknik Boundary Value Analysis untuk Pengujian Aplikasi Penjualan Menggunakan Metode Black Box Testing. Jurnal Informatika Universitas Pamulang, $\quad 5(2), \quad 129-135$. doi:10.32493/informatika.v5i2.5366 